Provided for non-commercial research and education use. Not for reproduction, distribution or commercial use.

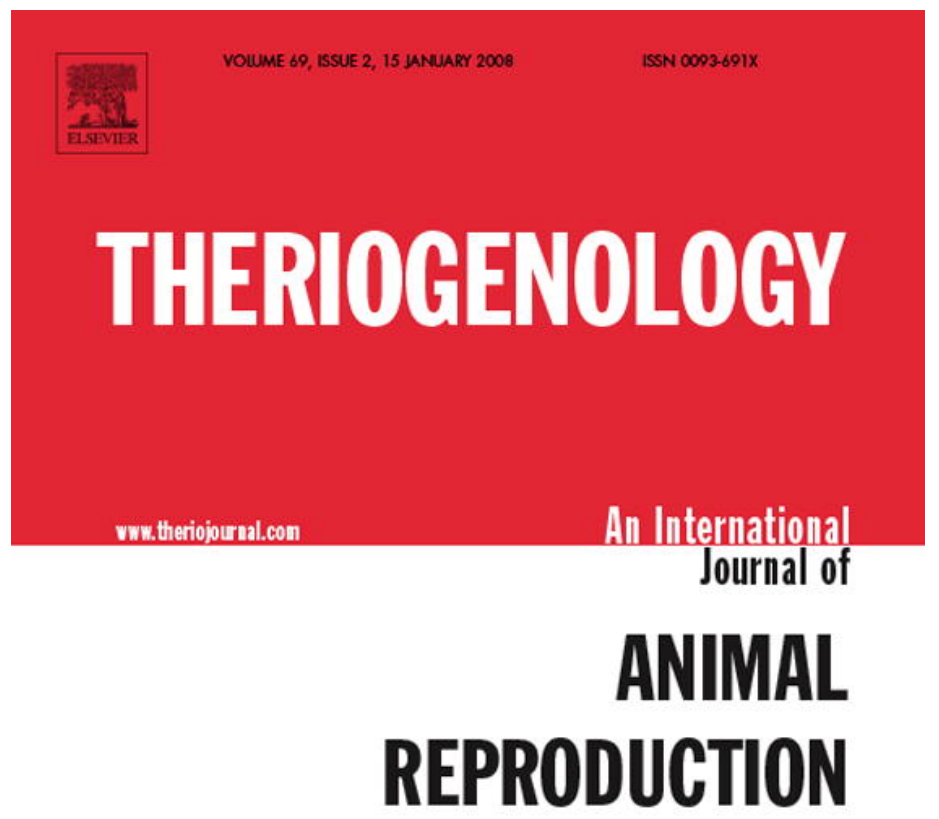

This article was published in an Elsevier journal. The attached copy

is furnished to the author for non-commercial research and education use, including for instruction at the author's institution, sharing with colleagues and providing to institution administration.

Other uses, including reproduction and distribution, or selling or licensing copies, or posting to personal, institutional or third party websites are prohibited.

In most cases authors are permitted to post their version of the article (e.g. in Word or Tex form) to their personal website or institutional repository. Authors requiring further information regarding Elsevier's archiving and manuscript policies are encouraged to visit:

http://www.elsevier.com/copyright 


\title{
Seasonal effects on the endocrine pattern of semi-captive female Asian elephants (Elephas maximus): Timing of the anovulatory luteinizing hormone surge determines the length of the estrous cycle
}

\author{
C. Thitaram ${ }^{\text {a,b,* }}$, J.L. Brown ${ }^{\text {c }}$, P. Pongsopawijit ${ }^{\text {a }}$, S. Chansitthiwet ${ }^{\mathrm{d}}$, \\ W. Wongkalasin ${ }^{\text {a }}$, P. Daram ${ }^{\text {a }}$, R. Roongsri ${ }^{\text {e }}$, A. Kalmapijit ${ }^{\mathrm{e}}$, \\ S. Mahasawangkul ${ }^{\text {d }}$, S. Rojansthien ${ }^{\mathrm{a}}$, B. Colenbrander ${ }^{\mathrm{b}}$, \\ G.C. van der Weijden ${ }^{b}$, F.J.C.M. van Eerdenburg ${ }^{\mathrm{b}}$ \\ ${ }^{\text {a }}$ Faculty of Veterinary Medicine, Chiang Mai University, Chiang Mai 50100, Thailand \\ ${ }^{\mathrm{b}}$ Faculty of Veterinary Medicine, Utrecht University, Yalelaan 7, 3854CL Utrecht, The Netherlands \\ ${ }^{\mathrm{c}}$ Conservation and Research Center, National Zoological Park, Smithsonian Institution, Front Royal, VA 22630, USA \\ ${ }^{\mathrm{d}}$ Thai Elephant Conservation Center, National Elephant Institute, Forest Industry Organization, Lampang, Thailand \\ ${ }^{\mathrm{e}}$ Maesa Elephant Camp, Chiang Mai 50100, Thailand
}

Received 14 July 2007; received in revised form 2 September 2007; accepted 18 September 2007

\begin{abstract}
Better breeding strategies for captive Asian elephants in range countries are needed to increase populations; this requires a thorough understanding of their reproductive physiology and factors affecting ovarian activity. Weekly blood samples were collected for 3.9 years from 22 semi-captive female Asian elephants in Thai elephant camps to characterize LH and progestin patterns throughout the estrous cycle. The duration of the estrous cycle was $14.6 \pm 0.2$ weeks (mean \pm S.E.M.; $n=71$ ), with follicular and luteal phases of $6.1 \pm 0.2$ and $8.5 \pm 0.2$ weeks, respectively. Season had no significant effect on the overall length of the estrous cycle. However, follicular and luteal phase lengths varied among seasons and were negatively correlated $(r=-0.658$; $P<0.01)$. During the follicular phase, the interval between the decrease in progestin concentrations to baseline and the anovulatory $\mathrm{LH}($ anLH) surge varied in duration (average $25.9 \pm 2.0$ days, range 7-41, $n=23)$, and was longer in the rainy season $(33.4 \pm 1.8$ days, $n=10)$ than in both the winter $(22.2 \pm 4.5$ days, $n=5 ; P<0.05)$ and summer $(18.9 \pm 2.6$ days, $n=8 ; P<0.05)$. By contrast, the interval between the anLH and ovulatory LH (ovLH) surge was more consistent (19.0 \pm 0.1 days, range 18-20, $n=14)$. Thus, seasonal variation in estrous cycle characteristics were mediated by endocrine events during the early follicular phase, specifically related to timing of the anLH surge. Overall reproductive hormone patterns in Thai camp elephants were not markedly different from those in western zoos. However, this study was the first to more closely examine how timing of the LH surges impacted estrous cycle length in Asian elephants. These findings, and the ability to monitor reproductive hormones in range countries (and potentially in the field), should improve breeding management of captive and semi-wild elephants.
\end{abstract}

(C) 2008 Elsevier Inc. All rights reserved.

Keywords: Estrous cycle; Progestins; Lutenizing hormone; Seasonal effect; Asian elephant

\footnotetext{
* Corresponding author at: Faculty of Veterinary Medicine, Chiang Mai University, Chiang Mai 50100, Thailand. Tel.: +66 53 948015/55; fax: +6653274710 .

E-mail address: thitaram@chiangmai.ac.th (C. Thitaram).
} 


\section{Introduction}

The world's populations of Asian elephants (Elephas maximus), both in situ and ex situ, are decreasing at an alarming rate (many are at the brink of extinction). Therefore, it is crucial to breed elephants in captivity so that captive stocks do not need to be supplemented by removing animals from the wild [1]. Unfortunately, captive breeding programs worldwide have met with limited success and few ex situ elephant populations are self-sustaining. Therefore, more effort is needed to improve captive breeding management strategies and understand the basic reproductive physiology of elephants; this requires the ability to characterize the estrous cycle of individual elephants and to identify the most viable breeding candidates.

In general, the duration of the estrous cycle ranged from 14 to 18 weeks. The non-pregnant luteal phase, characterized by high progestin concentrations, ranged from 10 to 14 weeks, with an interluteal phase (or follicular phase) that lasted from 3-6 weeks (reviews [24]) During the interluteal period, two surges of luteinizing hormone (LH) occurred, a phenomenon not described in other species. The first LH surge (anovulatory LH, anLH; function unknown) did not induce ovulation, whereas ovulation was induced by the second LH surge (ovulatory LH, ovLH), which occurred 3 weeks later $[4,5]$. Estrous cycle lengths were often similar within an individual, with a large range (10-23 weeks) among females [6-11].

To date, the majority of endocrine studies on Asian elephants have been conducted on captive females living in western zoos. Under these conditions, climate, photoperiod and nutrition differed considerably from those in native habitats, factors known to influence endocrine function in other species. Whether these same influences impacted reproduction of females under managed conditions, e.g., Asian tourist camps, has never been studied. However, increased knowledge of the relationship between physiological parameters and timing of reproduction, particularly in tropical regions, could offer novel insights to improve breeding strategies [12].

The objective of the present study was to characterize the reproductive endocrinology of semi-captive Asian elephants in a range country, Thailand, and determine how estrous cyclicity was influenced by season.

\section{Materials and methods}

\subsection{Animal history and husbandry}

Twenty-two mature Asian elephant females (average age: $29.4 \pm 2.2$ years; range $12-43$ ) from the Thai
Elephant Conservation Center (National Elephant Institute, Forest Industry Organization, Lampang, Thailand, $n=16$ ) and Maesa Elephant Camp (Chiang Mai, Thailand, $n=6$ ) were evaluated and described in Table 1. Sixteen of these females were captive-born, and 13 had previously given birth to one or more calves. Elephants at both facilities worked as tourist trekking animals or performed in shows for no more than $3 \mathrm{~h}$ daily (between 08.00 and 15.00). During the day and when not working, female elephants were chained in a shed among different female groups and provided grass, banana, sugar cane, hay, rice grains, and water ad libitum. Later in the afternoon, they were separately tethered with a $30 \mathrm{~m}$ long chain to forage in different areas of the forest overnight. Health examination was performed by a veterinarian once or twice annually, and an individual medical record was maintained. Body condition score was assessed as described by Wemmer et al. [13]. Females were kept separate from bulls, but exposed to bulls regularly at a distance. In case of increased sexual behavior during the late follicular phase of the cycle, the cow and a bull were placed in the forest to mate during the daytime, under observation of the mahout.

\subsection{Blood sampling and hormone analysis}

A 10-mL blood sample was collected from an ear vein once a week for $12-45$ consecutive months. When progestin concentrations decreased to baseline (i.e., during the follicular phase), blood was collected daily (at the same time each day) until concentrations again increased. Blood samples were allowed to clot at room temperature for $1-2 \mathrm{~h}$, and then centrifuged $(2000 \times g$ for $5 \mathrm{~min}$ ) to separate serum from blood cells. Serum was stored in $1.5 \mathrm{~mL}$ aliquots at $-20{ }^{\circ} \mathrm{C}$.

Progestins and luteinizing hormone (LH) were analyzed by enzyme immunoassay (EIA) as described previously $[14,15]$. The progesterone EIA [16] utilized a monoclonal progesterone antibody (1:10,000; Quidel clone \#425), horseradish peroxidase-conjugated progesterone label $(1: 40,000$; C. Munro, University of California-Davis, Davis, CA, USA), and progesterone standards (catalog \#P0130; Sigma Chemical Co., St. Louis, MO, USA). This antibody crossreacted with a variety of reduced pregnanes in serum and excreta in a wide range of species, including elephants. Sensitivity of the assay was $0.03 \mathrm{ng} / \mathrm{mL}$. The inter-assay coefficient of variation (CV) for the high concentration control was $15.1 \%$ and for the low control was $9.4 \%$.

The LH EIA utilized a monoclonal antibovine LH antiserum (518- $\left.\mathrm{B}_{7}\right)$, a biotin-conjugated ovine LH label, 
Table 1

Summary of female elephants evaluated in this study housed at the National Elephant Institute (Em1-Em16) and the Maesa Elephant Camp (Em17Em22)

\begin{tabular}{|c|c|c|c|c|c|}
\hline Animal & Age & Origin & $\begin{array}{l}\text { Body condition } \\
\text { score }(\text { full score }=11)\end{array}$ & $\begin{array}{l}\text { Reproductive } \\
\text { history }\end{array}$ & Recent reproductive status \\
\hline Em1 & 24 & Captive born & 9 & Parity 2 & $\begin{array}{l}\text { Pregnant, postpartum period } \\
\text { and normal estrous cycle }\end{array}$ \\
\hline Em2 & 23 & Not available & 10 & Parity 1 & $\begin{array}{l}\text { Pregnant, postpartum period and } \\
\text { normal estrous cycle }\end{array}$ \\
\hline Em3 & 24 & Donated from Myanmar & 10 & Parity 2 & $\begin{array}{l}\text { Pregnant, postpartum period } \\
\text { and normal estrous cycle }\end{array}$ \\
\hline Em4 & 45 & Captive born & 9 & Parity 2 & Normal cycling \\
\hline Em5 & 25 & Donated from Myanmar & 10 & Nulliparous & Normal cycling \\
\hline Em6 & 41 & Captive born & 9 & Parity 2 & Irregular cycling \\
\hline Em7 & 12 & Captive born & 8.5 & Nulliparous & Normal cycling \\
\hline Em8 & 12 & Captive born & 9 & Nulliparous & Irregular cycling \\
\hline Em9 & 44 & Captive born & 10 & Parity 3 & Normal cycling \\
\hline Em10 & 45 & Captive born & 10.5 & Parity 4 & Normal cycling \\
\hline Em11 & 31 & Captive born & 10 & No data & Normal cycling \\
\hline Em12 & 21 & Captive born & 6.5 & Nulliparous & Elevated progestins without cycling \\
\hline Em13 & 28 & Captive born & 9 & Nulliparous & Ovarian inactivity \\
\hline Em14 & 35 & Captive born & 7.5 & Parity 1 & Dystocia and retained dead fetus \\
\hline Em15 & - & Not available & 8 & Parity 1 & Normal cycling \\
\hline Em16 & 38 & Captive born & 8 & Parity 1 & Pregnant \\
\hline Em17 & 21 & Wild caught & 8.5 & Parity 1 & Pregnant and postpartum period \\
\hline Em18 & 21 & Captive born & 8 & Nulliparous & Normal cycling \\
\hline Em19 & 28 & Captive born & 8 & Parity 2 & Normal cycling and pregnant \\
\hline Em20 & 28 & Captive born & 7.5 & Nulliparous & Normal cycling \\
\hline Em21 & 34 & Wild caught & 7.5 & Nulliparous & Irregular cycling \\
\hline Em22 & 38 & Captive born & 8 & Parity 1 & Irregular cycling \\
\hline
\end{tabular}

horseradish peroxidase-conjugated streptavidin (cata$\log$ \#1089153; Roche Diagnostics, Indianapolis, IN, USA) and bovine LH (NIH-LH-B10; AFP-5551B) standards [17]. The biotinylated LH was prepared using an EZ-Link ${ }^{\mathrm{TM}}$ Sulfo-NHS-LC-Biotinylation kit (cata$\log$ \#21430; Pierce, Rockford, IL, USA). Sensitivity of the assay was $0.16 \mathrm{ng} / \mathrm{mL}$. The inter-assay coefficient of variation $(\mathrm{CV})$ for the high concentration control was $7.60 \%$ and for the low control was $8.47 \%$.

The progestin and LH EIAs were validated for elephant serum by demonstrating parallelism between serially diluted samples and the respective standard curve, and $90 \%$ recovery of added standard hormone to pooled samples [14].

\subsection{Estrous cycle determination}

From the calculation of average progestin concentrations during the follicular and luteal phases as described [18], a cut-off value of $0.3 \mathrm{ng} / \mathrm{mL}$ was used to identify a baseline. The onset of the luteal phase was defined as the first point at which serum progestin concentrations rose above $0.3 \mathrm{ng} / \mathrm{mL}$, and then remained elevated for at least 2 weeks. The estrous cycle was defined as the interval between successive increase in progestins $>0.3 \mathrm{ng} / \mathrm{mL}$.

\subsection{Seasonal and environmental determination}

Lengths of the estrous cycle, luteal and follicular phases were calculated for the three major seasons in Thailand: rainy season (16 May-15 October), winter (16 October-15 February) and summer (16 February15 May). Data regarding average temperature, humidity and daylight length in each month of the study period at $18.47^{\circ}$ north latitude was obtained (The Northern Meteorological Center, Meteorological Department, Ministry of Information and Communication Technology, Chiang Mai, Thailand), and a temperaturehumidity index (THI) was calculated [19]. Some estrous cycles, luteal and follicular phases overlapped two seasonal; therefore, the season of each cycle or phase was determined by the season in which the majority of that cycle or phase occurred.

\subsection{Statistical analysis}

Estrous cycle characteristics were compared among seasons using a mixed model method (SPSS 12.0; SPSS Inc., Chicago, IL, USA) with estrous cycle, luteal phase and follicular phase length as random effects, and season as the fixed effect $(\alpha=0.05)$, followed by a 


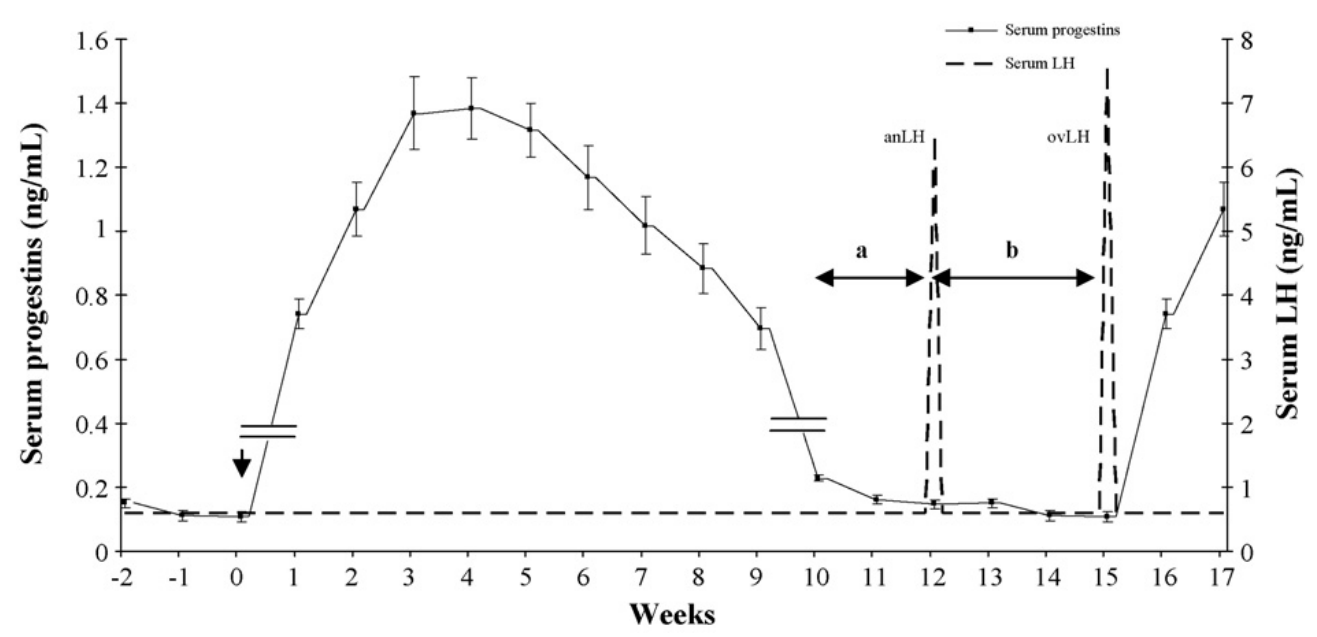

Fig. 1. Mean ( \pm S.E.M.) serum concentrations of progestins and LH throughout the estrous cycle $(n=71$ cycles) in 13 normal cycling Asian elephant females maintained under semi-captive conditions in Thailand. Day 0 was based on the first significant rise in serum progestins above baseline and estimated to be the time of ovulation as synchronization ( $\downarrow$ ). The interval between the decrease in progestin concentrations to baseline and the anLH surge (a) was quite variable, whereas the interval between the anLH and ovLH surges (b) was relatively consistent.

Bonferroni test. Data were presented as mean$\mathrm{s} \pm$ S.E.M. Data were normally distributed; thus, Pearson's bivariate correlations were used to test the relationship between follicular and luteal phase lengths $(\alpha=0.05)$. The effect of season on the mean interval between the decrease in progestin concentration to baseline and the anLH surge was calculated by one-way ANOVA and a Bonferroni pairwise multiple comparison procedure $(\alpha=0.05)$.

One-way ANOVA was used to determine the effect of season on mean progestin concentration, temperature, humidity, daylight length and THI $(\alpha=0.05)$. There was no homogeneity of variance for mean temperature, humidity and THI; therefore, a BrownForsythe and Welsch statistics test was used to test the multiple comparisons of means between groups $(\alpha=0.05)$.

\section{Results}

Of the 22 elephants studied, 13 were cycling and exhibited a total of 71 normal ovarian cycles (Table 1). Regular cyclicity was observed in the youngest (12 years) and oldest (45 years) females. Mean serum progestin and LH concentration across the estrous cycle are shown in Fig. 1. The average estrous cycle length was $14.6 \pm 0.2$ weeks (range 10-19), with a luteal phase length of $8.5 \pm 0.2$ weeks (range 4-13) and a follicular phase length of $6.1 \pm 0.2$ weeks (range 3-11). Average temperature (range $13.6-37 .{ }^{\circ} \mathrm{C}$ ), humidity

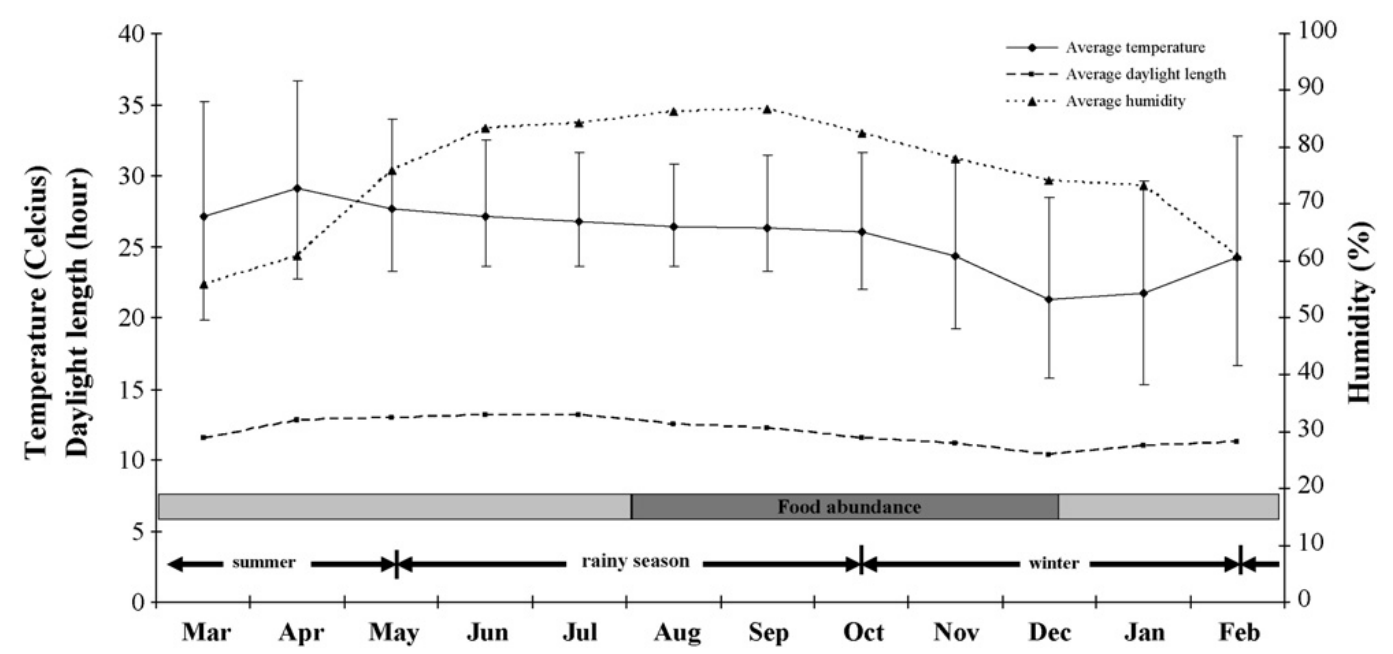

Fig. 2. Average temperature (maximum and minimum), humidity and daylight length in each month across the three major seasons in Thailand (during the study period). 
Table 2

Mean ( \pm S.E.M.) duration of the estrous cycle, follicular and luteal phases of Asian elephants during the rainy season, winter and summer, with the number of cycles recorded for each season

\begin{tabular}{lllllll}
\hline & Estrous cycle (weeks) & No. & Luteal phase (weeks) & No. & Follicular phase (weeks) & No. \\
\hline Rainy season & $14.9 \pm 0.3$ & 28 & $8.7 \pm 0.3$ & 26 & $6.6 \pm 0.3$ & 25 \\
Winter & $14.4 \pm 0.3$ & 21 & $8.2 \pm 0.4$ & 23 & $5.8 \pm 0.4$ & 22 \\
Summer & $14.5 \pm 0.3$ & 22 & $8.5 \pm 0.4$ & 22 & $5.9 \pm 0.3$ \\
& $14.6 \pm 0.2$ & 71 & $8.5 \pm 0.2$ & 71 & $6.1 \pm 0.2$ & 71 \\
\hline
\end{tabular}

(range 47.1-90.6\%) and daylight period (range 10.4$13.2 \mathrm{~h}$ ) are shown (Fig. 2). The forest vegetation was most abundant during the second part of the rainy season and the first half of winter. Mean temperature, humidity, daylight length and THI were different across seasons $(P<0.05)$; however, progestin concentrations did not differ $(P=1.0)$. The THI (range 59.9-88.3\%) was highest in the late summer and early rainy season. The average lengths of the estrous cycle, and luteal and follicular phases in each season are shown (Table 2). There was no seasonal effect on overall cycle length $(P=0.45)$, or duration of the luteal $(P=0.60)$ or follicular phases $(P=0.24)$.

Within the 71 cycles, there was a negative correlation between the lengths of the luteal and follicular phases ( $r=-0.658 ; P<0.01$; Fig. 3). The lengths of luteal and follicular phases, and overall cycles, were inconsistent both within and among the individual females. No estrous synchronization was observed among the females living in the same elephant camp. The body

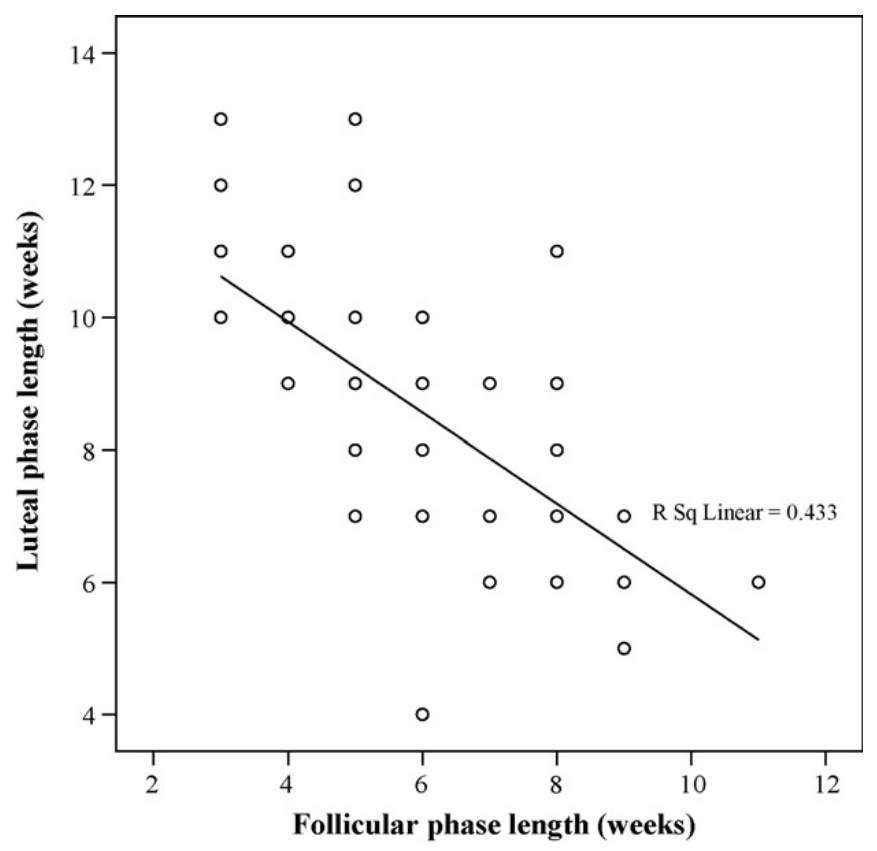

Fig. 3. Correlation between lengths of the luteal and follicular phases (over 71 estrous cycles) in Asian elephants. condition and health of normal and irregular cycling elephants were not markedly different. Only one elephant with a low body condition score (6.5) had elevated progestins without estrous cycles. Daily serum samples were collected from 10 of the 13 normally cycling elephants; 23 anLH and 23 ovLH surges were detected. The interval between the decrease in progestin concentrations to baseline and the anLH surge was $25.9 \pm 2.0$ days (range $7-41, n=23$ ), which was more variable than the interval between the anLH and ovLH surges $(19.0 \pm 0.1$ days; range $18-20, n=14)$. The interval between the decrease in progestin concentrations to baseline and the anLH surge during the rainy season was longer than that in both winter $(P=0.033)$ and summer $(P=0.001$; Table 3$)$.

\section{Discussion}

This study confirmed that general estrous cycle characteristics such as overall cycle length and the interval between anLH and ovLH surges, were similar between elephants in temperate-climate zoos $[3-5,20]$ and semi-captive animals living in northern Thailand. However, with the benefit of a detailed analysis, this is the first report that the follicular phase pattern of Thai elephants was significantly affected by season. Across all seasons, the interval between the decrease in progestin concentrations to baseline and the first anLH surge was more variable (range 7-41 days) than that reported for other Asian elephants (range 16-23 days; $[5,14])$, as well as between the anLH and ovLH surges (range 18-20 days). The 26-day overall mean interval to the anLH surge was also longer than that reported for African (12 days [20]) and Asian (19 days [5]) elephants living in western zoos. Upon closer inspection, the difference in early follicular phase dynamics in Thai elephants was due to a longer interval between the decrease in progestin concentrations to baseline and the anLH surge during the rainy season only. Though not significant $(P=0.239)$, elephants also had a longer overall follicular phase length during this season. By comparison, intervals during the winter and summer 
Table 3

Mean ( \pm S.E.M.) intervals between the decrease in progestin concentrations to baseline and the anLH surge in Asian elephants across the three major seasons in Thailand

\begin{tabular}{lrlr}
\hline Season & No. & Mean \pm S.E.M. (days) & Range \\
\hline Rainy & 10 & $33.4 \pm 1.8 \mathrm{a}$ & $25-41$ \\
Winter & 5 & $22.2 \pm 4.5 \mathrm{~b}$ & $12-37$ \\
Summer & 8 & $18.9 \pm 2.6 \mathrm{~b}$ & $7-28$ \\
& 23 & $25.9 \pm 2.0$ & $7-41$ \\
\hline
\end{tabular}

Within a column, values without a common letter differed $(P<0.005)$.

months were 22 and 19 days, respectively, not vastly different from other reports in Asian elephants $[5,14]$.

A similar seasonal influence on early follicular phase activity has not been documented for elephants in western zoos. The cause of this effect in Thai elephants was not known, but might be due to thermoregulatory stress in response to sultry weather conditions, as reflected by the high THI in the late summer and early rainy season. Elephants have a relatively low-body surface to volume ratio and could be susceptible to overheating. Therefore, a hot, humid environment might alter activity of the hypothalamo-pituitary-adrenal (HPA) and/or hypothalamic-pituitary-ovarian (HPO) axes during the early follicular phase, decreasing GnRH secretion and delaying an LH surge $[21,22]$. By contrast, once the first LH surge occurred, subsequent endocrine events appeared to be more spontaneous, or at least not affected to the same degree by external factors. Thus, in these animals, overall cycle length was more dependent on timing of resumption of gonadotropic activity after the removal of progestin block at the end of the luteal phase, than on any other endocrine parameter. Only one other report described temporary ovarian inactivity (i.e., extended nonluteal periods) up to 15 weeks in duration in a group of three captive African elephants in North America [23]. Unlike that study, however, longer intervals to the anLH surge were only found in the winter months and were associated with time spent indoors. Thus, although not analogous, results of these two studies suggested more work was needed to determine the effect of climate, both hot and cold, on gonadotropin secretion and ovarian activity in elephants. In dairy cattle, heat stress increased adenocorticotropin (ACTH) and cortisol that suppressed or affected the preovulatory LH surge and estrous [24,25].

Seasonal influences related to food and water availability also impacted ovarian steroid activity in freeranging African elephants [12,26]. In the mare, a seasonal polyestrous breeder, the luteal phase is relatively constant, whereas the follicular phase is variable and the major determinant of the estrous cycle length [27], not unlike that observed in Thai elephants. Furthermore, the follicular phase in mares is shorter during the peak breeding season (late spring, summer and early fall) and longer during the transitional period (early spring and late fall) [28]. For elephants living in a natural situation and tropical climate, having estrous periods occur more often in winter and summer would ensure parturition 22 months later during the late rainy season and winter when food was more abundant, not unlike that described for free-ranging African elephants [29].

Long and short luteal phases have been reported in African elephants [30], but not in Asian elephants. In African elephants, short luteal phases were only 2-3 weeks in duration, which was shorter than the shortest luteal phase of 4 weeks and overall means of approximately 8.5 weeks in the present study. Interestingly, luteal and follicular phase lengths were often negatively correlated, with a short luteal phase followed by a long follicular phase, and vice versa. This resulted in fewer aberrant overall cycle lengths as compared to individual luteal and follicular phase lengths. Currently, there is no explanation for this relationship, or published reports as to whether it occurs in other elephant populations.

In contrast to the variation between serum progestins return to baseline level and the anLH surge, the interval between the two LH surges was very consistent at approximately 19 days, similar to previous reports in both species [3-5,20,31,32]. As in other mammals, the ovLH surge in elephants plays a role in ovulation, terminates the follicular phase and initiates the luteal phase [3-5,20,31,32]. By contrast, the function of the anLH surge remained unclear. It appeared, however, that timing of the anLH surge had a significant influence on the overall length of the follicular phase. Two distinct waves of follicular development occurred at 3week intervals during the follicular phase, at least in African elephants [31], presumably under the influence of FSH [33]. For unknown reasons, the timing of the first wave was not as tightly controlled as that of the second wave. Longitudinal ultrasound examinations are needed to determine whether the wide variability in the timing of the anLH surge was related to a delay in initiation of the first follicular wave. From an ecological standpoint, a prolonged follicular phase might be necessary for females to attract mating bulls, which often travelled long distances in search of estrous females. To that end, pheromones in urine were known to occur prior to the anLH surge and reached maximal concentrations just before the ovLH surge [34].

In summary, a seasonal effect on the reproductive cycle of Asian elephants living in a range country, 
Thailand was identified, and apparently mediated by timing of the anLH surge, relative to removal of the progestin block at the end of the luteal phase. This timing has a direct effect on the overall length of the follicular phase. A similar relationship has not been documented in other populations of Asian or African elephants. Thus, it is clear that long-term reproductive monitoring of elephants living in different regions of the world is needed to more fully understand the factors affecting reproductive potential. For any captive breeding program, determination of estrous is an important management tool to ensure females mate with bulls at the appropriate stage of the cycle. This is especially true for working elephants in Thailand, where there is often conflict between the time and labour necessary to breed elephants and daily work activities. Given the importance of elephants in Thai culture and other Asian range countries, it is imperative to develop practical strategies to sustain and conserve this species, both in situ and ex situ.

\section{Acknowledgements}

We thank National Research Council of Thailand, Royal Thai Government scholarship, Treasure Our Elephants Fund Thailand, and the Smithsonian Women's Committee, USA for research funding; Dr. Jan van den Broek and Mr. Pichai Jirawattanapong, Utrecht University for statistical assistance; Dr. Stephan J. Dieleman, Utrecht University, and Dr. Thomas Hildebrandt, Institute of Zoo Biology and Wildlife Research, Berlin for scientific assistance; Ms. Sue Walker, Ms. Karen Steinman, Ms. Nicole Abbodanza from Smithsonian Conservation and Research Center for endocrine laboratory support; Dr. Gannigar Nimtrakul, Chiang Mai zoo and Mr. Kongphop Thilaongam for additional endocrine laboratory assistance; Dr. Preecha Puangkham, Mr. Worawit Rojanaphaitoon, National Elephant Institute, Mr. Choochart Kulmapijit, Maesa Elephant camp for allowing long-term study of the elephants; all the mahouts and staffs of Thai Elephant Conservation Center and Maesa Elephant camps for their assistance; and Ms. Linda McPhee for proof reading.

\section{References}

[1] Sukumar R. A brief review of the status, distribution and biology of wild Asian elephants Elephas maximus. Int Zoo $\mathrm{Yb}$ 2006;40:1-8.

[2] Hildebrandt TB, Goeritz F, Hermes R, Reid C, Dehnhard M, Brown JL. Aspects of the reproductive biology and breeding management of Asian and African elephants: Elephas maximus and Loxodonta africana. Int Zoo Yb 2006;40:20-40.
[3] Brown JL. Reproductive endocrine monitoring of elephants: an essential tool for assisting captive management. Zoo Biol 2000;15:347-67.

[4] Hodges JK. Endocrinology of the ovarian cycle and pregnancy in the Asian (Elephas maximus) and African (Loxodonta africana) elephant. Anim Reprod Sci 1998;53:3-18.

[5] Brown JL, Schmitt DL, Bellem A, Graham LH, Lehnhardt J. Hormone secretion in the Asian elephant (Elephas maximus): characterization of ovulatory and anovulatory luteinizing hormone surges. Biol Reprod 1999;61:1294-9.

[6] Brown JL, Citino SB, Bush M, Lehnhardt J, Phillips LG. Cyclic patterns of luteinizing hormone, follicle-stimulating hormone, inhibin and progesterone secretion in the Asian elephant (Elephas maximus). J Zoo Wildl Med 1991;22: 49-57.

[7] Brown JL, Lehnhardt J. Serum and urinary hormones during pregnancy and the peri- and postpartum period in an Asian elephant (Elephas maximus). Zoo Biol 1995;14:555-64.

[8] Dehnhard M, Heistermann M, Goritz F, Hermes R, Hildebrandt T, Haber H. Demonstration of 2-unsaturated C19-steroids in the urine of female Asian elephants, Elephas maximus, and their dependence on ovarian activity. Reproduction 2001;121: 475-84.

[9] Hess DL, Schmidt AM, Schmidt MJ. Reproductive cycle of the Asian elephant (Elephas maximus) in captivity. Biol Reprod 1983;28:767-73.

[10] Olsen JH, Chen CL, Boules MM, Morris LS, Coville BR. Determination of reproductive cyclicity and pregnancy in Asian elephants (Elephas maximus) by rapid radioimmunoassay of serum progesterone. J Zoo Wildl Med 1994;25:349-54.

[11] Plotka ED, Seal US, Zarembka FR, Simmons LG, Teare A, Phillips LG, et al. Ovarian function in the elephant: luteinizing hormone and progesterone cycles in African and Asian elephants. Biol Reprod 1988;38:309-14.

[12] Wittemyer G, Ganswindt A, Hodges K. The impact of ecological variability on the reproductive endocrinology of wild female African elephants. Horm Behav 2007;51:346-54.

[13] Wemmer C, Krishnamurthy V, Shrestha S, Hayek LA, Thant M, Nanjappa KA. Assessment of body condition in Asian elephants (Elephas maximus). Zoo Biol 2006;25:187-200.

[14] Brown JL, Goritz F, Pratt-Hawkes N, Hermes R, Galloway M, Graham LH, et al. Successful artificial insemination of an Asian elephant at the National Zoological Park. Zoo Biol 2004;23:4563.

[15] Thitaram C, Pongsopawijit P, Thongtip N, Angkavanich T, Chansittivej S, Wongkalasin W, et al. Dystocia following prolonged retention of a dead fetus in an Asian elephant (Elephas maximus). Theriogenology 2006;66:1284-91.

[16] Munro C, Stabenfeldt G. Development of a microtitre plate enzyme immunoassay for the determination of progesterone. $\mathrm{J}$ Endocrinol 1984;101:41-9.

[17] Graham LH, Bolling J, Miller G, Pratt-Hawkes N, Joseph S. Enzyme-immunoassay for the measurement of luteinizing hormone in the serum of African elephants (Loxodonta africana). Zoo Biol 2002;21:403-8.

[18] Heistermann M, Trohorsch B, Hodges JK. Assessment of ovarian function in the African elephant (Loxodonta africana) by measurement of 5a-reduced progesterone metabolites in serum and urine. Zoo Biol 1997;16:273-84.

[19] Steadman RG. The assessment of sultriness. Part I. A temperature-humidity index based on human physiology and clothing science. J Appl Meteorol 1979;18:861-73. 
[20] Kapustin N, Critser JK, Olson D, Malven PV. Nonluteal estrous cycles of 3-week duration are initiated by anovulatory luteinizing hormone peaks in African elephants. Biol Reprod 1996;55:1147-54.

[21] Tilbrook AJ, Turner AI, Clarke IJ. Effects of stress on reproduction in non-rodent mammals: the role of glucocorticoids and sex differences. Rev Reprod 2000;5:105-13.

[22] Ferin M. Stress and the reproductive cycle. J Clin Endocrinol Metab 1999;84:1768-74

[23] Schulte BA, Feldman E, Lambert R, Oliver R, Oliver R. Temporary ovarian inactivity in elephants: relationship to status and time outside. Physiol Behav 2000;71:123-31.

[24] Younas M, Fuquay JW, Smith JAE, Moore AB. Estrous and endocrine responses of lactating Holsteins to forced ventilation during summer. J Dairy Sci 1993;76:430-6.

[25] Stobel DP, Moberg GP. Effect of adrenocorticotropin and cortisol on luteinizing hormone surge and estrous behavior of cows. $\mathrm{J}$ Dairy Sci 1982;65:1016-24.

[26] Foley CAH, Papageorge S, Wasser SK. Noninvasive stress and reproductive measures of social and ecological pressure in freeranging African elephants. Conserv Biol 2001;15:1134-42.

[27] Pryor P, Tibary A. Management of estrous in the performance mare. Clin Tech Equine Pract 2005;4:197-209.
[28] Adams GP, Bosu WTK. Reproductive physiology of the nonpregnant mare. Vet Clin North Am Equine Pract 1988;4:161-76. An overview and update.

[29] Wittemyer G, Rasmussen HB, Douglas-Hamilton I. Breeding phenology in relation to NDVI variability in free-ranging African elephant. Ecography 2007;30:42-50.

[30] Brannian JD, Griffin F, Papkoff H, Terranova PF. Short and long phases of progesterone secretion during the oestrous cycle of the African elephant (Loxodonta africana). J Reprod Fertil 1988; 84:357-65.

[31] Hermes R, Olson D, Göritz F, Brown JL, Schmitt DL, Hagan D, et al. Ultrasonography of the estrous cycle in female African elephants (Loxodonta africana). Zoo Biol 2000;19:369-82.

[32] Czekala NM, MacDonald EA, Steinman K, Walker S, Garrigues NW, Olson D. Estrogen and LH dynamics during the follicular phase of the estrous cycle in the Asian elephant. Zoo Biol 2003;22:443-54.

[33] Brown JL, Hildebrandt TB, Theison W, Neiffer DL. Endocrine and ultrasound evaluation of a non-cycling African elephant: identification of an ovarian follicular cyst. Zoo Biol 1999;18: 223-32.

[34] Rasmussen LE, Lazar J, Greenwood DR. Olfactory adventures of elephantine pheromones. Biochem Soc Trans 2003;31:137-41. 